\title{
The Impact of the Reactivity to Stress in Teachers with Voice Problems
}

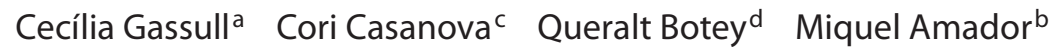 \\ ${ }^{a}$ Faculty of Sciences of Education and ${ }^{b}$ Department of Methods, Universitat Autònoma de Barcelona, \\ 'Department of Logopedics, Universitat Ramon Llull-Blanquerna and d Voice Therapist/Psychologist, \\ Private Practice, Barcelona, Spain
}

\section{Key Words}

Stress · Occupational voice $\cdot$ Teachers $\cdot$ Voice Handicap

Index $\cdot$ Stress Reactivity Index

\begin{abstract}
Aims: One of the objectives of our study on voice and vocal health was to find out whether there is a relation between the reactivity to stress and voice problems in teachers. $\mathbf{M a}$ terials and Methods: For this, we used a sample of 447 individuals amongst future teachers and teachers in active service, since they form a group with both a high index of voice problems and stress. In order to gather the necessary information for the study, we applied the Voice Handicap Index and the 'índice de reactividad al estrés' (IRE; Stress Reactivity Index). Results: The results indicate that those individuals with voice problems have a greater reactivity to stress. It was observed that some items of the IRE show a relatively great difference between the groups with and without voice problems. The majority of these items concern vegetative signs that are linked to aspects of voice emission. Conclusion: Reactivity to stress is a useful factor to bear in mind in teachers with voice problems.

Copyright $\odot 2010$ S. Karger AG, Basel
\end{abstract}

\section{Introduction}

The teaching group is one of the work groups with the highest risk of suffering from voice problems [1-6]. Many epidemiological studies highlight this risk in teachers [7-
9], which worsens when considering primary school teachers in particular. A recent investigation by Munier and Kinsella [10], who analyzed the prevalence of voice problems in teachers, shows that only $20 \%$ of them have not suffered from voice problems. Teachers generally attribute their voice problems to their job and there is a higher index of absenteeism for this reason [11].

Although the etiology of voice problems is diverse, it seems that physical and psychoemotional variables are the main risk factors $[5,12]$. However, having to speak for many hours [13] at high intensity is also an important factor to take into account.

Together with voice problems, stress also frequently occurs in this group. Teachers attribute its origin to causes such as having to work with little motivated pupils, being assessed by third parties or carrying a heavy workload [14]. Furthermore, they have to speak or sing during long periods in stressful situations with intensity and good voice quality and in environments which require an inefficient and harmful use of the voice $[15,16]$.

In jobs such as teaching, where an efficient and healthy voice is essential, important elements come into play, such as position, degree of muscle intensity [17, 18], breathing, laryngeal operation or a good use of the resonating cavities for an ideal amplification of the voice. An imbalance in these elements could negatively affect voice emission.

The stress system coordinates the general stress response, which occurs when a stressor agent of any type exceeds a threshold [19]. We know that stress is a useful response as long as it is adequate to the causing stimulus and does not overrule the control and response capaci-

\section{KARGER \\ Fax +4161306 1234 \\ E-Mail karger@karger.ch}

www.karger.com (c) 2010 S. Karger AG, Basel

$1021-7762 / 10 / 0622-0035 \$ 26.00 / 0$

Accessible online at:

www.karger.com/fpl
Cecília Gassull

Universitat Autònoma de Barcelona

Edifici G6 Facultat de Ciències de l’Educació

ES-08193 Bellaterra (Spain)

Tel. +3493581 1679, Fax +3493581 3299, E-Mail cecilia.gassull@ uab.cat 
Table 1. Distribution of voice problems in students and teachers

\begin{tabular}{lrlll}
\hline & Number & Percent & $\chi^{2}$ & $\mathrm{p}$ \\
\hline Students $(\mathrm{n}=252)$ & & & & \\
$\quad$ With no voice problems & 196 & 77.8 & & \\
$\quad$ With voice problems & 56 & 22.2 & 4.67 & 0.031 \\
Teachers ( $\mathrm{n}=195)$ & & & & \\
$\quad$ With no voice problems & 134 & 68.7 & & \\
$\quad$ With voice problems & 61 & 31.3 & & \\
\hline
\end{tabular}

Voice problems $=$ VHI score $>9$; no voice problems $=$ VHI score $\leq 9$.

ties. The organism is prepared to react to situations of diverse nature, but damage to physical or psychic health is caused when the factors that induce stress have a marked intensity, frequency and duration which exceed the mechanisms that the subject uses to face them [20].

For many decades studies have been carried out in order to understand how stress affects health and illnesses $[21,22]$. These studies show how the emotional reactions or stress are correlated with different cardiovascular [23], circulatory [24] disorders, amongst others.

González de Rivera [22] calls the individual way of reacting to possible stressful situations 'reactivity to stress' and defines it as a group of response norms (cognitive, behavioral, emotional, and vegetative) which determine the effects of external stress factors.

The investigation carried out by Demmink-Geertman and Dejonckere [25, 26] seems interesting to us. They studied the relation between nonorganic dysphonia and the subjective experience of a dysfunction of the autonomic nervous system (neurovegetative lability) and came to the conclusion that subjects with nonorganic dysphonia report significantly more complaints or symptoms related to a possible dysfunction of the autonomic nervous system than subjects with no voice problems.

In the field of investigations into the relation between stress and voice problems, we found some interesting studies which suggest that individuals with functional dysphonia have personality features or temperament characteristics which can predispose them to suffer from voice problems [27]. In a similar line of investigation but with a wider range of variables and types of voice pathology, Roy et al. [28] observed that patients with functional dysphonia and vocal nodule, apart from having specific personality features, showed higher reactivity to stress compared to patients with spastic dysphonia or unilateral vocal fold paralysis. Van Mersbergen et al. [29] found similar results in patients diagnosed with functional dysphonia who showed the same level of reactivity to stress as those individuals with social anxiety.

Our aim was to check if, in the teaching group, the way to react to stress was closely related to the perception of voice problems.

\section{Materials and Methods}

In order to gather data, we used a sample of 447 individuals (252 students and 195 teachers), enrolled in the following way: teacher training students of the courses 2006-2007 and 20072008 who study the subject 'voice education' in the UAB (Universitat Autònoma de Barcelona) and teachers from nursery and primary education schools in Barcelona who work with children aged between 3 and 11 years.

We used the Voice Handicap Index (VHI) [30] in order to discriminate between those individuals with voice problems and those who do not perceive voice difficulties. A score above 9 indicated a voice problem. In order to assess the individual response tendency to stressful situations we used the 'índice de reactividad al estrés' (IRE; Stress Reactivity Index) [31,32], which measures the usual norms of cognitive, emotional, vegetative and behavioral response to situations perceived as potentially damaging, dangerous or unpleasant, on a 5-point Likert scale (from 0 to 4). This test allows to analyze the total IRE or the 4 response norms separately (vegetative IRE, emotional IRE, cognitive IRE, and behavioral IRE). If the categorized score is below 0.6 , the reactivity to stress is considered to be low; if it is between 0.6 and 1 , the reactivity to stress is considered to be high but not worrying, and if it is above 1 , the reactivity to stress is considered to be too high. In order to show the global difference of intensity of the responses between individuals with or without voice problems, we used scores (from 0 to 138) obtained from the sum of all the responses given.

The data were analyzed using the statistical program SPSS (v. 15). For continuous outcome variables that were normally distributed, the Student $t$ test was used. For discrete outcome variables, $\chi^{2}$ tests were used. The significance level was set at $\mathrm{p} \leq$ 0.05 .

\section{Results}

The data show that there is an important percentage of participants with voice problems. This rate is significantly higher in the teaching group $(\mathrm{p}=0.031$; table 1$)$.

The scores of the IRE indicate a significantly $(\mathrm{p}<$ 0.001 , $t$ test) higher reactivity to stress in individuals (teachers and controls) with voice problems (mean $=44.8$, $\mathrm{SD}=13.51)$, compared with those without voice problems (mean $=33.7, \mathrm{SD}=14.85$ ). This tendency is found in both the teachers and controls (table 2).

Figure 1 presents the relation of voice problems and IRE scores in students and teachers. A relatively great 
Fig. 1. The relation between voice problems and IRE scores in students and teachers. The percentage of individuals with scores that are considered to be low, high but not worrying, and too high are indicated. Significance level $\mathrm{p}<0.001\left(\chi^{2}\right.$ test).

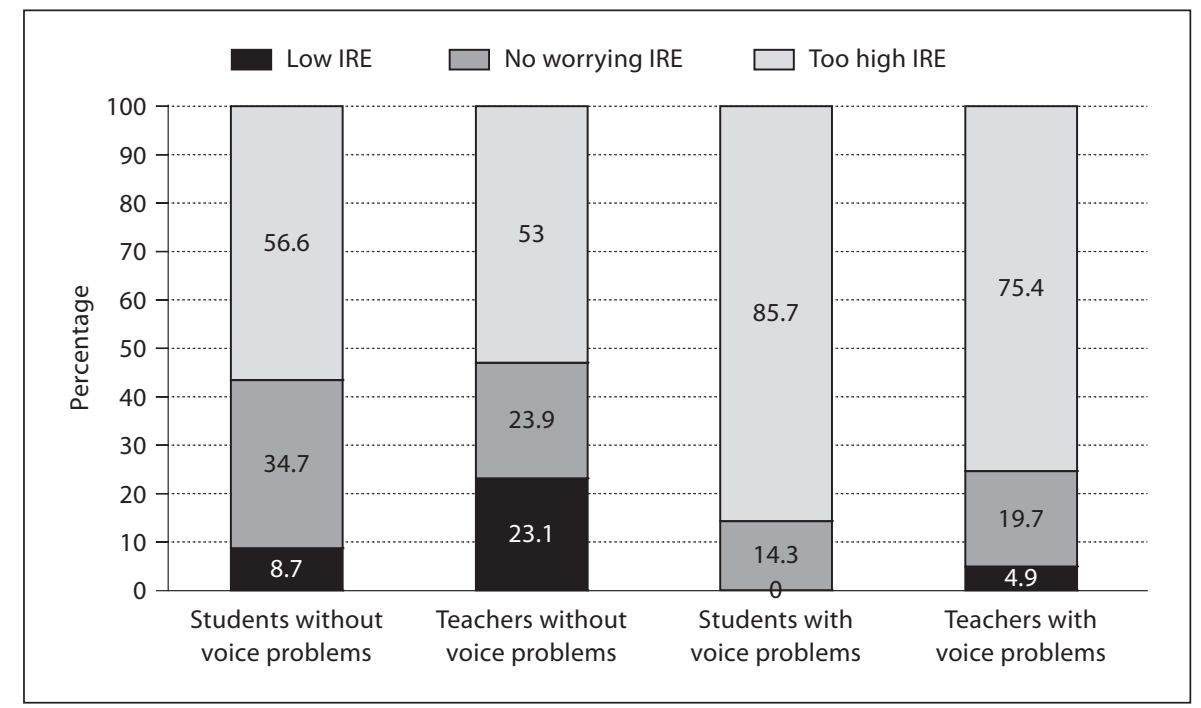

Table 2. Mean and standard deviation of the IRE scores of the students and teachers

\begin{tabular}{lrll}
\hline & Number & Percent & Score \\
\hline Students $(\mathrm{n}=252)$ & & & \\
$\quad$ With no voice problems & 196 & 77.78 & $37.0 \pm 14.00$ \\
$\quad$ With voice problems & 56 & 22.22 & $47.4 \pm 13.93$ \\
Teachers $(\mathrm{n}=195)$ & & & \\
$\quad$ With no voice problems & 134 & 68.7 & $33.7 \pm 16.29$ \\
$\quad$ With voice problems & 61 & 31.3 & $42.3 \pm 12.00$ \\
\hline
\end{tabular}

Voice problems $=$ VHI score $>9$; no voice problems $=$ VHI score $\leq 9$.

percentage of students and teachers who perceive voice problems showed a reactivity to stress that is too high, compared to students and teachers without voice problems. Moreover, there is an almost inexistent or very low proportion of individuals with voice problems and low reactivity to stress.

Since reporting voice problems and IRE scores are similar in students and teachers, the following analysis was carried out with the students and teachers in one group. Significant differences were found between individuals with and without voice problems in all the response norms of the IRE (vegetative, emotional, cognitive, and behavioral) (table 3).

The Student $t$ test was applied in order to observe whether certain items of the IRE show a higher reactivity in the groups with or without voice problems. We found

The Impact of the Reactivity to Stress in

Teachers with Voice Problems
Table 3. The scores of the IRE subtests of individuals with (VHI score $>9$ ) and without voice problems (VHI score $\leq 9$ )

\begin{tabular}{|c|c|c|c|}
\hline & Mean $\pm \mathrm{SD}$ & $\mathrm{t}$ value & $\mathrm{p}$ value \\
\hline \multicolumn{4}{|l|}{ Vegetative IRE } \\
\hline Without voice problems & $1.0 \pm 0.50$ & $-5,978$ & $<0.001$ \\
\hline With voice problems & $1.3 \pm 0.45$ & & \\
\hline \multicolumn{4}{|l|}{ Emotional IRE } \\
\hline Without voice problems & $1.1 \pm 0.65$ & $-5,849$ & $<0.001$ \\
\hline With voice problems & $1.5 \pm 0.64$ & & \\
\hline \multicolumn{4}{|l|}{ Cognitive IRE } \\
\hline Without voice problems & $1.3 \pm 0.54$ & $-3,031$ & 0.003 \\
\hline With voice problems & $1.5 \pm 0.58$ & & \\
\hline \multicolumn{4}{|l|}{ Behavioral IRE } \\
\hline Without voice problems & $1.1 \pm 0.55$ & $-3,072$ & 0.002 \\
\hline With voice problems & $1.5 \pm 0.50$ & & \\
\hline
\end{tabular}

The level of significance (p) is estimated by the $t$ test.

that 17 of them are significantly more present in the group with voice problems (table 4). It is worth mentioning that 10 of these 17 items (IRE4, IRE5, IRE10, IRE12, IRE13, IRE14, IRE17, IRE19, IRE21, and IRE22) refer to vegetative responses.

\section{Discussion}

The results obtained indicate that extreme reactivity to stress is significantly more present in the group of individuals with voice problems. 
Table 4. Most present items in the group with voice problems

\begin{tabular}{|c|c|c|c|}
\hline $\begin{array}{l}\text { Num- } \\
\text { ber }\end{array}$ & $\begin{array}{l}\text { Items of the IRE in the group with } \\
\text { voice problems }\end{array}$ & $\begin{array}{l}\mathrm{t} \\
\text { value }\end{array}$ & $\begin{array}{l}\mathrm{p} \\
\text { value }\end{array}$ \\
\hline IRE1 & Concern, inability to relax and be calm & $-2,908$ & 0.004 \\
\hline IRE4 & $\begin{array}{l}\text { Desire to sigh, chest oppression, feeling } \\
\text { of breathlessness }\end{array}$ & $-4,947$ & $<0.001$ \\
\hline IRE5 & Palpitations, tachycardia & $-2,446$ & 0.013 \\
\hline IRE6 & Feelings of depression and sadness & $-4,822$ & $<0.001$ \\
\hline IRE10 & Nausea, sickness, instability & $-2,069$ & 0.040 \\
\hline IRE12 & Tingling or sleepiness of hands, face ... & $-2,493$ & 0.013 \\
\hline IRE13 & Stomach upsets, abdominal pain ... & $-2,972$ & 0.003 \\
\hline IRE14 & Headache & $-4,250$ & $<0.001$ \\
\hline IRE16 & Decrease in activity & $-2,320$ & 0.021 \\
\hline IRE17 & Loss of sexual appetite or sexual dysfunction & $-3,341$ & 0.001 \\
\hline IRE19 & Sleepiness & $-3,311$ & 0.002 \\
\hline IRE20 & Apprehension, feeling of getting ill & $-5,811$ & $<0.001$ \\
\hline IRE21 & Exhaustion or excessive tiredness & $-5,475$ & $<0.001$ \\
\hline IRE22 & Frequent urination & $-3,283$ & 0.001 \\
\hline IRE24 & $\begin{array}{l}\text { Feelings of aggressiveness or increase } \\
\text { in irritability }\end{array}$ & $-2,117$ & 0.035 \\
\hline IRE27 & Need of being alone and not being disturbed & $-2,905$ & 0.004 \\
\hline IRE29 & Anxiety, more liability to fear, fears & $-3,686$ & $<0.001$ \\
\hline
\end{tabular}

The level of significance (p) is estimated by the t test.
However, a high reactivity to stress does not necessarily entail having voice problems, although the pertinent study shows that individuals who suffer voice problems tend to have too high a reactivity to situations which they perceive as stressful.

It was also observed that individuals with voice problems present higher reactivity levels in all 4 types of response of the IRE, i.e. vegetative, emotional, cognitive and behavioral, but mostly in the vegetative type. This statement is derived from the 17 items found as the most discriminative in the population with voice problems. Of these 17 items, 10 are of the vegetative type. These results are in accordance with those of Demmink-Geertman and Dejonckere [26], who showed a relation between vocal dysfunction and neurovegetative symptomatology.

In conclusion, the results of the pertinent study indicate that individuals with a high IRE score present higher vulnerability to suffering from voice problems. Thus, we agree with Kooijman et al. [12] about the importance of considering the psychoemotional factors in the diagnosis and treatment of voice.

The way responses of the vegetative type can affect voice production and consequently generate voice problems remains unresolved. This field should be further explored.

\section{References}

1 Ilomäki I, Mäki I, Laukkanen A: Vocal symptoms among teachers with and without voice education. Logoped Phoniatr Vocol 2005;30:171-174.

2 Velsvik Bele I: The teacher's voice: vocal training in teacher education. Scand J Educ Res 2008;52:41-57.

3 Fritzell B: Voice disorders and occupation. Logoped Phoniatr Vocol 1996;21:7-12.

-4 Simberg S, Sala E, Vehmas K, Laine A: Changes in the prevalence of vocal symptoms among teachers during a twelve-year period. J Voice 2005; 19:95-102.

5 Thomas G, Kooijman PG, Donders AR, Cremers WR, de Jong FICRS: The voice handicap of student-teachers and risk factors perceived to have a negative influence on the voice. J Voice 2007;21:325-336.

-6 Smith E, Lemke J, Taylor M, Kirchner L, Hoffman H: Frequency of voice problems among teachers and other occupations. J Voice 1998; 12:480-488.
7 Urrutikoetxea A, Ispizua A, Matellanes F: Pathologie vocale chez les professeurs: Une étude vidéo-laryngo-stroboscopique de 1,046 professeurs. Rev Laryngol Otol Rhinol 1995; 116:255-262.

8 Etiemble J: La voix: Ses troubles chez les enseignants. Une expertise collective de l'inserm. Paris, Institut Nacional de la Santé et de la Recherche Médicale, 2007, pp 343350.

\$ Preciado-López J, Pérez-Fernández C, Calzada-Uriondo M, Preciado-Ruiz, P: Epidemiological study of voice disorders among teaching professional of la Rioja, Spain. J Voice 2008;22:489-508.

10 Munier C, Kinsella R: The prevalence and impact of voice problems in primary school teachers. Occup Med 2008;58:74-76.

11 Roy N, Merrill RM, Thibeault S, Gray SD, Smith EM: Voice disorders in teachers and the general population. J Speech Lang Hear Res 2004;47:542-551.

\12 Kooijman PG, de Jong FICRS, Thomas G, Huinck W, Donders R, Graamans K, Schutte HK: Risk factors for voice problems in teachers. Folia Phoniatr Logop 2006;58:159-174.
13 Vilkman E: Voice problems at work: a challenge for occupational safety and health arrangement. Folia Phoniatr Logop 2000;52: $120-125$.

14 Kyriacou C: Teacher stress: directions for future research. Educ Rev 2001;53:27-35.

15 Mattiske J, Oates JM, Greenwood KM: Vocal problems among teachers: a review of prevalence, causes, prevention, and treatment. J Voice 1998;12:489-499.

16 Pithers RT, Soden R: Scottish and Australian teacher stress and strain: a comparative study. Br J Educ Psychol 1998;68:269-279.

-17 Bruno E, de Padova A, Napolitano B, Marroni $\mathrm{P}$, Batelli R, Ottaviani F, Alessandrini M: A voice disorders and posturography: variables to define the success of rehabilitative treatment. J Voice 2009;23:71-75.

18 Kooijman PGC, de Jong FICRS, Oudes MJ, Huinck W, van Acht H, Graamans K: Muscular tension and body posture in relation to voice handicap and voice quality in teachers with persistent voice complaints. Folia Phoniatr Logop 2005;57:134-147. 
19 Chrousos GP, Gold PW: The concepts of stress and stress system disorders. Overview of physical and behavioral homeostasis. JAMA 1992;267:1244-1252.

20 Suárez O, Sardíñas J, Rondón R: Tratamiento integral del estrés. 2007. http://www.apfem. com/articulodelmes/07-10-Octubre/0710-T ratamiento\%20del\%20Estres.pdf.

21 Miguel-Tobal JJ, González Ordi H: Emociones y salud: Perspectivas actuales en el estudio de los trastornos cardiovasculares. Ansiedad Estrés 2003;9:121-144.

22 González de Rivera JL: Factores de estrés y vulnerabilidad a la enfermedad. Monogr Psiquiatr 1991;3:1-5.

23 Tinoco Mesquita C, Lucas de Mesquita AC: Miocardiopatia adrenérgica: o estresse pode causar uma cardiopatia aguda? Arq Bras Cardiol 2005;84:283-284.
24 Shiga T, Kasanuki H: Influence of mental stress on blood pressure in hypertensives. Clinic All-round 2004;53:2543-2545.

25 Demmink-Geertman L, Dejonckere PH:Nonorganic habitual dysphonia and autonomic dysfunction. J Voice 2002;16:549-559.

26 Demmink-Geertman L, Dejonckere PH: Neurovegetative symptoms and complaints before and after voice therapy for nonorganic habitual dysphonia. J Voice 2006;20:242250.

27 Roy N, Bless DM: Personality trait and psychological factors in voice pathology: a foundation for future research. J Speech Lang Hear Res 2000;43:737-748.

28 Roy N, Bless D, Heisey D: Personality and voice disorders: a multitrait-multidisorder analysis. J Voice 2000;14:521-548.
29 Van Mersbergen M, Patrick C, Glaze L: Functional dysphonia during mental imagery: testing the trait theory of voice disorders. J Speech Lang Hear Res 2008;51:14051423.

30 Deary I, Webb A, MacKenzie K, Wilson J, Carding P: Short, self-report voice symptom scales: psychometric characteristics of the voice handicap index-10 and the performance questionnaire. Otolaryngology 2004; 131:232-235.

31 González de Rivera JL: Crisis emocionales. Cómo salir airoso y reforzado de nuestras crisis. Madrid, Espasa Práctico, 2006.

32 Rodríguez-Abuín MJ, González de Rivera JL, Hernández-Herrero L, De la Hoz JL, Monterrey AL: Reactividad al estrés en disfunción témporo-mandibular. www. psiquiatrica.com/psiquiatria/vol3num3/ artic_2.htm. 